\title{
ECONOMICAL INVESTIGATION OF RAPID PROTOTYPING
}

\author{
Péter Ficzere', Lajos Borbás ${ }^{2}$, Ádám Török ${ }^{3}$ \\ ${ }^{1,2}$ Department of Vehicle Parts and Drives, Budapest University of Technology and Economics, H-1111 \\ Budapest, Bertalan L. u. 2. \\ ${ }^{3}$ Department of Transport Economics, Budapest University of Technology and Economics, H-1111 \\ Budapest, Bertalan L. u. 2.
}

Received 25 November 2012; accepted 9 July 2013

\begin{abstract}
Usage of rapid prototyping gain developers, designers and engineers more time and consume less money and save more resources. In this article authors investigated the economic possibilities of rapid prototyping. In concurrent engineering, different tasks are tackled at the same time, and not necessarily in the usual order. Concurrent engineering is a method by which several teams within an organization work simultaneously to develop new products and allows more flexible approach. The concurrent engineering is a non-linear product or project design approach during which all phases of manufacturing operate at the same time.
\end{abstract}

Keywords: rapid prototyping, finite element analysis, material properties.

\section{Introduction}

Nowadays it takes less and less time to launch a new product, therefore the planning phase needs less time, too. Moreover, with the earliest possible elimination of the errors in planning, the costs of errors can also be significantly decreased. A rapid prototyping system should support maximal reuse and innovative combinations of existing methods, as well as simple and quick integration of new ones. On the basis of all these it is obvious that the role of prototypes has increased considerably, especially the functional prototypes, where the parts can be examined under the later working conditions and furthermore real workload analysis can be done. Another important aspect is to estimate computation time, cost and resources of the final system. Such estimation is essential in order to decide to which extent knowledge discovery can be applied (Mierswa et al., 2006). In this paper authors have investigated the economical aspect of rapid prototyping.

\section{The Role of Prototypes}

Formerly the prototypes were manufactured only at the end of the planning cycle and they were rather expensive and wasting lots of human resources, as the tools needed during the manufacturing were not available. Nevertheless nowadays the prototypes appear in a fairly early phase of planning. Usage of rapid prototyping gain developers, designers and engineers more time and money and save more resources (Ficzere and Borbas, 2009). Some decades ago 3D fabricating approaches were inaccurate. Most methods for fabricating were based on procedures that yielded twodimensional (2D) systems (Kovacs, 1998). There were a number of more specialized procedures-stereolithography (SLA) (Ikuta et al., 1994) laser-chemical three-dimensional (3D) writing (Bloomstein and Ehrlich, 1994) and modular assembly (Gonzalez et al., 1998) that yield 3D structures, but these methods were not ideally convenient either for prototyping or manufacturing and are not

\footnotetext{
${ }^{3}$ Corresponding author: torok.adam@kti.hu
} 
capable of making certain types of structures due to the heavy investment in machines and lots of human resource. Since then lot has been changed and due to heavy development better and more accurate methods have been invented recently for generating complex $3 \mathrm{D}$ assembly with less human and fiscal resources. Acceleration of the development of technology will continue and $3 \mathrm{D}$ printing will become usual technological method (Anderson et al., 2000). There are the socalled digital prototypes, which are $3 \mathrm{D}$ models used by CAD/CAM/CAE softwares. Through these models the shape can be seen, and we can perform finite element analysis on them regarding the possible constraints and loads. Also we can perform interference checking and production simulations (turning, milling and drilling) on them.

Rapid prototyping (RPT) often refers to a class of layer-based manufacturing technologies that first appeared for industry use about 25 years ago. In contrary to traditional material removal processes, these techniques build a part by gradually adding materials layer by layer (Kruth, 1991; Barequet and Kaplan, 1998). The processes are fully automatic. They offer a number of competitive advantages over traditional manufacturing processes and are particularly useful for rapid product development. Commonly used RPT processes include stereolithography (SLA), selective laser sintering (SLS), fused deposition modelling (FDM), laminated object manufacturing and $3 \mathrm{D}$ printing. Several issues in RPT, such as new processes, material properties, part surface quality, build time, applications and tooling are active research topics.

Stereolithography is an additive manufacturing process using a vat of liquid UV-curable photopolymer "resin"/liquid epoxy and a UV laser to build parts a layer at a time. On each layer, the laser beam/ray traces a part cross-section pattern on the surface of the liquid resin. Exposure to the UV laser light cures, solidifies the pattern traced on the resin and adheres it to the layer below (Limaye, 2006). Selective laser sintering (SLS) is an additive manufacturing technique that uses a high power laser (for example, a carbon dioxide laser) to fuse small particles of plastic, metal (direct metal laser sintering), ceramic, or glass powders into a mass that has a desired 3-dimensional shape. The laser selectively fuses powdered material by scanning cross-sections generated from a 3-D digital description of the part (for example from a CAD file or scan data) on the surface of a powder bed. After each cross-section is scanned, the powder bed is lowered by one layer thickness, a new layer of material is applied on top, and the process is repeated until the part is completed. Because finished part density depends on peak laser power, rather than laser duration, a SLS machine typically uses a pulsed laser. The SLS machine preheats the bulk powder material in the powder bed somewhat below its melting point, to make it easier for the laser to raise the temperature of the selected regions the rest of the way to the melting point (Yarlagadda and Narayanan, 2005). Fused deposition modelling (FDM) is an additive manufacturing technology commonly used for modelling, prototyping, and production applications. The technology was developed by S. Scott Crump in the late 1980s and was commercialized in 1990. The thermoplastics are liquefied and deposited by an extrusion head, which follows a tool-path defined by the CAD file. The materials are deposited in layers as fine as 0.005 -inch thick, and the part is built from the bottom up - one layer at a time. FDM works on an "additive" principle by laying down material in layers. A plastic filament or metal wire is unwound from a coil and supplies material to an extrusion 
nozzle which can turn the flow on and off (Vashishtha et al., 2011). 3D printing is a form of additive manufacturing technology where a three dimensional object is created by laying down successive layers of material. 3D printers are generally faster, more affordable and easier to use than other additive manufacturing technologies (Horvath and Harsanyi, 2010). $3 \mathrm{D}$ printers offer product developers the ability to print parts and assemblies made of several materials with different mechanical and physical properties in a single build process. Advanced 3D printing technologies yield models that closely emulate the look, feel and functionality of product prototypes. A 3D printer works by taking a 3D computer file to make a series of cross-sectional slices. Each slice is then printed one on top of the other to create the $3 \mathrm{D}$ object. Three-dimensional printing makes it as cheap to create single items as it is to produce thousands and thus undermines economies of scale. The PolyJet prototyping technology or Objet's patented PolyJet inkjet technology works by jetting state of the art photopolymer materials in ultrathin layers $(16 \mu \mathrm{m})$ onto a build tray layer by layer until the part is completed. The intuitive Objet studio $^{\mathrm{TM}}$ software manages the process. Each photopolymer layer is cured by UV light immediately after it is jetted, producing fully cured models that can be handled and used immediately, without post-curing. The gel-like support material, which is specially designed to support complicated geometries, is easily removed by hand and water jetting.

In the area for surface accuracy improvement and build time reduction, there have also been researches during the past decade on the optimization of build orientation and adaptive slicing. As a part is built up layer by layer with $\mathrm{RPT}$ processes, a staircase effect is a major factor affecting the surface smoothness. Its influence is determined by the layer thickness and the local part geometry. It depends on the fineness of the STL-file ${ }^{4}$ too. After the printing these materials allow the (finishing process if necessary). If the layer thickness is computed based on the local geometry, the staircase effect can then be controlled to a userspecified tolerance level. In general, there are two slicing approaches for the determination of the layer thickness, i.e. uniform slicing and adaptive slicing. Uniform slicing is the simplest approach for slicing a part at equal intervals. It is widely used for commercial RPT systems in industry today. It is however a compromising issue in determining the layer thickness. If the layer thickness is small, one obtains a smooth part. It may however result in many layers and long build time. On the other hand, if the layer thickness is large, the build time is short, but one may end up with a part having a large staircase effect (just the case of small radius curvature, because on vertical and horizontal planes isn't staircase effect). For resolving the above compromising issue, adaptive slicing has been proposed to generate a variable layer thickness based on the local surface geometry and a pre-specified smoothness requirement (Dolenc and Makela, 1994; Weiyin et al., 2004).

The rapid prototypes can also be grouped by the way they are used. In one of the groups our aim is to make the shape perfect and to show the appearance of the product. This model can undergo ergonomical examinations. The second type can also be called functional model. Functional models are built in, they undergo fit investigation, and they are used for checking whether the model being under planning can carry out its function or not. Thus the whole structure has to function under real loads/conditions. The aim of the third type of prototypes is to test how it can be manufactured.

${ }^{4} \mathrm{An}$ STL-file is a triangular representation of a 3D surface geometry. 


\section{Economical Analysis}

Direct materials are those materials that become an integral part of the finished product and that can be physically and conveniently traced to it. Direct Material Cost $\left(\mathrm{DMC}_{\mathrm{t}, \mathrm{i}}\right)$ is actually the cost of any materials that are used in the final product. In our case DMC is time $(t)$ and production unit $(i)$ dependent. Sometimes it is not worth the effort to trace the costs of relatively insignificant materials to the end products. InDirect Material Costs $\left(\right.$ IDMC $\left._{t}\right)$ are those for activities or services that benefit more than one project. In our case IDMC is a time $(t)$ dependent variable. Their precise benefits to a specific project are often difficult or impossible to trace. The term Direct Labour Cost $\left(\mathrm{DLC}_{\mathrm{t}, \mathrm{i}}\right)$ is reserved for those labour costs that can be essentially traced to individual units of products. Direct labour is sometime called touch labour, since direct labour workers typically touch the product while it is being made. The labour cost of assembly line workers, for example, is a direct labour cost. In our case DLC is time $(t)$ and production unit $(i)$ dependent. Labour costs that cannot be physically traced to the creation of products, or that can be traced only at a great cost and inconvenience, are termed InDirect Labour Cost $\left(\mathrm{IDLC}_{\mathrm{t}}\right.$ ) and treated as part of manufacturing overhead, along with indirect materials. Indirect labour includes the labour costs of supervisors, materials handlers, and night security guards. Although the efforts of these workers are essential to production, it would be either impractical or impossible to accurately trace their costs to specific units of product. In this case IDLC is a time $(t)$ dependent variable. To this cost elements it is necessary to add the Manufacturing Overhead Cost (MOC). Manufacturing Overhead Cost include items such as indirect material, indirect labour, maintenance and repairs on production equipment and heat and light, property taxes, depreciation, and insurance on manufacturing facilities. Derived from the above mentioned MOC is also time $(t)$ dependent variable. So Cost Of Manufacturing (COM) can be calculated by Eq. (1):

$$
\operatorname{COM}_{i, t}=\frac{\sum_{t=t_{0}}^{t=t_{1}}\left(\sum_{i=1}^{n}\left(D M C_{t, i}+D L C_{t, i}\right)+I D M C_{t}+I D L C_{t}\right)}{n}
$$

where,

COMt,i: Cost of Manufacturing in the $t$ investigation time (from $t_{0}$ to $t_{1}$ ) at producing unit $i$

DMCt,i: Direct Material Cost in the $t$ investigation time (from $t_{0}$ to $t_{1}$ ) at producing unit $i$

DLCt,i: Direct Labour Cost in the $t$ investigation time (from $t_{0}$ to $t_{1}$ ) at producing unit $i$

IDMCt,i: InDirect Material Cost in the $t$ investigation time (from $t_{0}$ to $t_{1}$ ) at producing unit $i$

IDLCt,i: InDirect Labour Cost in the $t$ investigation time (from $t_{0}$ to $t_{1}$ ) at producing unit $i$

$\mathrm{n}$ : number of produced units

To simplify Eq. (1):

$$
\operatorname{COM}_{i, t}=\frac{\sum_{t=t_{0}}^{t=t_{1}}\left(\sum_{i=1}^{n}\left(D M C_{t, i}+D L C_{t, i}\right)+M O C_{t}\right)}{n}
$$

where,

MOCt,i: Manufacturing Overhead Cost in the $t$ investigation time (from $t_{0}$ to $t_{1}$ ) at producing unit $i$ 
Furthermore to have the Market Price (MP) the Research and Development Costs (RDC), the Revenue (R), Taxes (T) and the Marking Costs (MC) need to be added.

$M P_{t, i}=\operatorname{COM}_{t, i}+\frac{\sum_{t=t_{0}}^{t=t_{1}}\left(\sum_{i=1}^{n} R D C_{t, i}+R_{t, i}+T_{t, i}+M C_{t, i}\right)}{n}$

where,

MPt,i: Market Price in the $t$ investigation time (from $t_{0}$ to $t_{1}$ ) at producing unit $i$

$\mathrm{RDCt}, \mathrm{i}$ : Research and Development Cost in the $t$ investigation time (from $t_{0}$ to $t_{1}$ ) at producing unit $i$

$\mathrm{Rt}$,i: Revenue in the $t$ investigation time (from $t_{0}$ to $t_{1}$ ) at producing unit $i$

$\mathrm{Tt}$,i: Taxes in the $t$ investigation time (from $t_{0}$ to $t_{1}$ ) allocated to unit $i$

MCt,i: Marketing Cost in the $t$ investigation time (from $t_{0}$ to $t_{1}$ ) at producing unit $i$

With the rapid prototyping the direct costs and the indirect cost can be significantly lowered compared to regular linear production chains. Rapid prototyping is an approach which allows crucial design decisions as early as possible. Rapid prototyping is the automatic construction of physical objects using additive manufacturing technology. The use of additive manufacturing for rapid prototyping takes virtual designs from computer aided design (CAD) or animation modelling software, transforms them into thin, virtual, horizontal cross-sections (16-30 $\mu \mathrm{m})$ and then creates successive layers until the model is complete. With additive manufacturing, the machine reads the data from a $\mathrm{CAD}$ drawing and lays down successive layers of liquid, powder, or sheet material, and in this way builds up the model from a series of cross sections. These layers, which correspond to the virtual cross section from the CAD model, are joined together or fused automatically to create the final shape. The primary advantage to additive fabrication is its ability to create almost any shape or geometric feature. With this technology time and money can be saved, errors occur earlier in planning phase. Rapid prototyping is a relatively young spreading technology (Fig. 1).

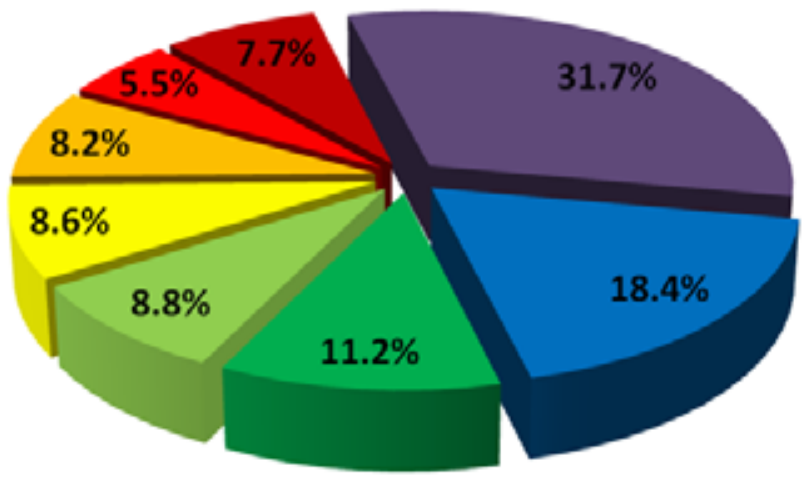

Motor vehicles

- Consumer products

Business machines

Medical

Academic

Aerospace

Government/Military

- Others

Fig. 1.

Percentage Use of Rapid Prototyping Worldwide as of Year 2000

Source: Vashishtha et al. (2011) 
According to the up-to-date economic results a real fork lift model estimated cost is $2.5 \mathrm{M}$ USD and the production time is 52 weeks. Compare to this with digital prototyping the printing would cost about 75k USD and would be ready in 12 weeks. The gained advantages from earlier market penetration have not been calculated (Falk, 2010).

\section{Conclusion}

Auto-call-back procedures, which are very trademark destroying and costly (not only the procedure itself but the caused effect in trust) can be significantly decreased due to the fact that with rapid prototyping the planning phase needs less time and the elimination of the errors can be done in the earliest possible phase within the planning phase. Therefore the costs of errors can also be significantly decreased as a huge advantage that can be assigned to rapid prototyping. A rapid prototyping system should support maximal reuse and innovative combinations of existing methods, as well as simple and quick integration of new ones. Therefore rapid prototyping is an emerging technology within the vehicle production sector and further research is essential.

\section{References}

Anderson, J.R.; Chiu, D.T.; Jackman, R.J.; Cherniavskaya, O.; McDonald, J.C.; Wu, H.; Whitesides, S.H.; Whitesides, G.M. 2000. Fabrication of Topologically Complex ThreeDimensional Microfluidic Systems in PDMS by Rapid Prototyping, Analitical Chemistry. DOI: http://dx.doi. org/10.1021/ac9912294, 72(14): 3158-3164.

Barequet, G.; Kaplan, Y. 1998. A data front-end for layered manufacturing, Computer-Aided Design. DOI: http:// dx.doi.org/10.1016/S0010-4485(97)00076-6, 30(4): 231-243.

Bloomstein, T.M.; Ehrlich, D.J. 1992. Laser-chemical three-dimensional writing for microelectromechanics and application to standard-cell microfluidics, Journal of Vacuum Science \& Technology B: Microelectronics and Nanometer Structures. DOI: http://dx.doi.org/10.1116/1.586023, 10(6): 2671-2674.

Dolenc, A.; Makela, I. 1994. Slicing procedures for layered manufacturing techniques, Computer-Aided Design. DOI: http://dx.doi.org/10.1016/0010-4485(94)90032-9, 26(2): 119-126.

Falk, G. 2010. Advantages of Rapid Prototyping [In Hungarian: Gyorsprototípus gyártás elönyei], SimDay 2010 Users Day - October 14, 2010.

Ficzere, P.; Borbás, L. 2009. Investigation of material properties of rapid-prototyping products for finite element analysis [in Hungarian: Gyors-prototípus készitö eljárással gyártott termékek anyagtulajdonságainak meghatározása végeselemes analízis számára] GÉP 60:(10-11).36-39.

Gonzalez, C.; Smith, R.L.; Howitt, D.G.; Collins, S.D. 1998. MicroJoinery: concept, definition, and application to microsystem development, Sensors and Actuators A: Physical. DOI: http://dx.doi.org/10.1016/S09244247(98)00074-0, 66(1-3): 315-332. 
Horváth, E.; Harsányi, G. 2010. Optimization of Fluidic Microchannel Manufacturing Processes in Low Temperature Co-Fired Ceramic Substrates, Periodica Polytechnica Electrical Engineering and Computer Science. DOI: http://dx.doi.org/10.3311/pp.ee.2010-1-2.08, 54(1-2): 79-86.

Ikuta, K.; Hirowatari, K.; Ogata, T. 1994. Three dimensional micro integrated fluid systems IFS fabricated by stereo lithography. In Proceedings of the IEEE Workshop on Micro Electro Mechanical Systems. DOI: http://dx.doi. org/10.1109/MEMSYS.1994.555588, 1-6.

Kovacs, G.T.A. 1998. Micromachined Transducers Sourcebook. McGraw-Hill: New York. 911 p.

Kruth, J.P. 1991. Material increase manufacturing by rapid prototyping technologies, CIRP Annals - Manufacturing Technology. DOI: http://dx.doi.org/10.1016/S00078506(07)61136-6, 40(2): 603-614.

Limaye, A. 2006. Process Planning Method For Mask Projection Stereolithography Under Parameter Uncertainty, PhD Dissertation. 28 p.
Mierswa, I.; Scholz, M.; Klinkenberg, R.; Wurst, M.; Euler, T. 2006. YALE: Rapid Prototyping for Complex Data Mining Tasks. In Proceedings of the 12th ACM SIGKDD international conference on Knowledge discovery and data mining. DOI: http://dx.doi. org/10.1145/1150402.1150531, 935-940.

Vashishtha, V.K.; Makade, R.; Mehla, N. 2011. Advancement of Rapid Prototyping in Aerospace Industry - A Review, International Journal of Engineering Science and Technology, 3(3): 2486-2493.

Weiyin, M.; Wing-Chung, B.; Peiren, H. 2004. NURBSbased adaptive slicing for efficient rapid prototyping, Computer-Aided Design. DOI: http://dx.doi.org/10.1016/j. cad.2004.02.001, 36(13): 1309-1325.

Yarlagadda, P.K.D.V.; Narayanan, S. 2005. GCMM 2004: 1st International Conference on Manufacturing and Management, Narosa Publishing House. 714 p. 